\title{
"Let the flesh instruct the mind": corpo, desejo e sinestesia nas crônicas vampirescas de Anne Rice ${ }^{1}$
}

"Let the flesh instruct the mind": body, desire, and synesthesia in Anne Rices' the vampire chronicles

Andrio de Jesus Rosa dos Santos

Universidade Federal de Santa Maria

Enéias Farias Tavares

Universidade Federal de Santa Maria

DOI: https://doi.org/10.5902/2176148537626

Resumo: Na obra da autora norte-americana Anne Rice, questões aparentemente paradoxais como materialidade/espiritualidade, profano/sagrado e natural/sobrenatural, ganham destaque, em enredos que ou orbitam discussões especulativas sobre a origem material do universo e suas possibilidades espirituais ou uma densa reflexão sobre os limites potenciais dos sentidos corpóreos, intensificados pela observação da natureza ou pela apreciação da arte. Isso quando a autora não contrapõe essas duas dimensões, como em A História do Ladrão de Corpos (1992) Lasher (1993), Memnoch (1995) e O Servo dos Ossos (1996), nos quais essas dimensões estão emparelhadas tanto na esfera do enredo quanto na da linguagem. Neste ensaio, nos debruçaremos sobre um desses eixos, aquele que tem a ver com a descrição, compreensão e intensificação dos sentidos corpóreos, esses intensificados pela natureza vampírica de seus protagonistas, em seu primeiro romance Entrevista com o Vampiro (1976). A partir das reflexões de Katherine Ramsland, Jennifer Smith e Terri R. Liberman, entre outros, demonstraremos como, através dos dramas de seus monstros, Rice indiretamente propõe uma intensificação das percepções corpóreas e sensitivas, não apenas no que concerne à percepção da natureza e da arte, como também ao próprio corpo e sua capacidade de perceber/vivenciar/recriar o entorno material.

Palavras-chave: Anne Rice. Crônicas Vampirescas. Corpo. Sinestesia.

Abstract: In Anne Rice's novels subjects apparently paradoxical - such as materiality and spirituality, profane and sacred, and natural and supernatural - have a special

1 O presente trabalho foi realizado com apoio da Coordenação de Aperfeiçoamento de Pessoal de Nível Superior - Brasil (CAPES) - Código de Financiamento 001. 
Andrio de

Jesus Rosa dos

Santos

Enéias Farias

Tavares

range of discussion. Such matters relate to debates concerning the origin of the material universe as well as its spiritual meaning, and to reflections about the limits of corporeal sensual appreciation, magnified by perceiving of art and nature. Rice usually counterparts these subjects, as in The Tale of the Body Thief (1992), Lasher (1993), Memnoch (1995), and Servant of the Bones (1996), novels in which such matters are approached by plot as well as expressed by working with the style. In this essay, we intend to discuss one of these questions, the one which relates to representation, understanding, and intensification of corporeal senses; intensification provided by the main character's vampire nature, as it can be read in Rice's first novel Interview with the Vampire (1976). In a dialogue with critics such as Katherine Ramsland, Jennifer Smith, and Terri R. Liberman, among others, we will demonstrate how - concerning her monsters' drama - Rice indirectly proposes an intensification of corporeal sensations, not just relating to the perception of art and nature, as well as the very capacity of the body to reconcile and recreate its material environment.

Keywords: Anne Rice. The Vampire Chronicles. Body. Synesthesia.

\section{Introdução}

Escrever sobre a ficção de Anne Rice é também escrever sobre as intermitências e dualidades que se relacionam com seus romances e sua recepção. A obra da autora estadunidense atrai tanto a atenção acadêmica quanto a do público mainstream. A razão disso pode ser encontrada nas características composicionais de suas obras, como caracterizações de personagens sofisticadas e enredos intrincados, como também no fato de que Rice estabelece um diálogo crítico com a tradição gótica (HAGGERTY, 1998). As obras da autora são frequentemente incluídas em um "escopo gótico", no qual aparecem ao lado de obras fundadores, como The Castle of Otranto (1764), de Horace Walpole, e The Mysteries of Udolpho (1794), de Ann Radcliffe, até autores contemporâneos, como Clive Barker e Stephen King. Mas diferente desses, Rice foca sua literatura de horror menos em temas e situações próprias do gênero e mais em explorações espirituais, culturais e filosóficas.

Gary Hoppenstand (1995) menciona que Rice influencia a estética e o comportamento de uma geração inteira de leitores, que mais tarde estariam associados ao movimento pós-punk e dark wave. Ao lado dessa reunião de leitores "góticos" trajados de preto, há leitores cristãos e conservadores. Jane Plumb (1990) e Eric Savoy (2002) discutem a razão por trás da abrangência do público da autora, rele- 
gando sua popularidade à mistura entre temas mais gerais e o terror de caráter fantástico na obra de Rice. Frequentemente, esta intermitência se relaciona a observações de caráter também estético e comportamental.

A religião Católica ocupa lugar central na vida da autora desde a infância em Nova Orleans. Rice, de 1960 até meados de 1990, renega e critica diversas questões do dogma Católico. Em 2002, a autora abraça o Catolicismo mais uma vez, dedicando-se à escrita de romances sobre a vida de Cristo. Em 2010, afasta-se novamente da instituição, principalmente devido às posições da Igreja, que Rice considerava retrógradas, a respeito de questões como homoafetividade e direitos LGBTQ+. Essa relação instável entre fé e filosofia se relaciona diretamente com o tipo de ficção que Rice escreve e os temas que desenvolve.

"Let the flesh instruct the mind" dição de "dark fiction". Conforme a autora escreve em Essay On Earlier Works ${ }^{2}$, isso pode ser visto nas obras de autores que a influenciaram; poetas como Shakespeare, Milton e Dante, e romancistas como Melville, Mary Shelley e Dickens. No mesmo ensaio, a autora comenta que os três temas mais recorrentes em sua obra, se não os mais importantes, são "the continuing battle against evil", "the search for the good" e "the quest of the outcast for a context of meaning". Não espanta que, ora ou outra, surjam esses "monstros humanos", como Lestat ou Ramses, que podem ser lidos como representações da dual condição humana (RAMSLAND, 1991), apontamento que fornece uma importante ferramenta de leitura e interpretação da obra da autora.

A representação de uma personagem à margem, em busca de sentido, apresenta-se de fato como um tema recorrente na obra de Rice. Este é o caso de Louis, em Interview with the Vampire (1976). Em razão disso, com grande frequência sua obra é discutida em relação às Teorias de Gênero. Rice comenta que Interview with the Vampire "is about the near despair of an alienated being who searches the world for some hope that his existence can have meaning" (RICE, 2007). Sob esta ótica, os vampiros riceanos figurariam metáforas para o isolamento e a alienação social imposta a comunidade LGBTQ+ (FERRARO, 1990).

2 RICE, Anne. Essay On Earlier Works: TO MY READERS - On the Nature of My Earlier Works, annerice.com, 8/15/2007. Disponível em: <http://www.annerice.com/Bookshelf-EarlierWorks.html>. Acesso em: 21/02/2019. 
Rice mostra-se frequentemente interessada em tais questões, que aparecem, em maior ou menor grau, em praticamente todos os seus textos. Temos Yuri, David e Ash, na série sobre as bruxas Mayfair, The Lives of Mayfair Witches (1990-1994), que apresentam uma sexualidade fluida, marcada por um quê de dandismo. Em The Vampire Lestat (1985), Gabrielle,

Andrio de Jesus Rosa dos

Santos

Enéias Farias

Tavares a mãe do protagonista, que mais tarde torna-se sua filha e amante vampira, digladia-se com seu gênero; Gabrielle corta seus cabelos, pois deseja apresentar-se, vestir-se e agir a partir de uma noção cavalheiresca de "masculino", mas sua condição vampírica faz com que seus cabelos cresçam toda noite, lançando-a de volta no momento anterior à sua transformação pessoal e à sua condição biológica pré-determinada.

O interesse da autora por tais questões relaciona-se, em parte, ao período em que viveu com o esposo, Stan Rice, no bairro Haight-Ashbury, em San Francisco, nas décadas de 1960 a 1980. O bairro Haight-Ashbury viria a se tornar, durante o surgimento do movimento Hippie, assim como do New e Dark Wave, nas décadas de '70 e '80, um polo da contracultura nos EUA, contando com comunidades Hippies e Gays (SPANN, 2003). Rice, ao lado de seu marido, assistiu o surgimento desses movimentos e às metamorfoses da cultura ao seu redor. Em uma entrevista para o The New York Times, Rice comenta que "in the middle of Haight-Ashbury in the 1960s, I was typing away while everybody was dropping acid and smoking grass. I was known as my own square" (KELLERMAN, 1988) ${ }^{3}$.

Podemos mencionar algumas pesquisas que tratam da obra de Rice a partir da ótica dos estudos de gênero. Em Dark Angels: a study of Anne Rice's Vampire Chronicles (1998), Jane Plumb trata o termo "vampirismo" como metáfora para a homoafetividade, discutindo problemas de representação, preconceito e segregação social. Além disso, a autora examina o ato simbólico do consumo de sangue, na ficção de Rice, tratando-o como metáfora à histeria social relativa à disseminação da AIDS na década de '90, nos EUA. Em outro estudo, Anne Rice and Sexual Politics: The Early Novels (2000), James R. Keller se aproxima da questão da sexualidade em diversos romances da autora, tanto na saga The Vampire Chronicles, focando nas personagens Lestat e Louis, quanto em textos eróticos, como na séria Sleeping Beauty (1983-2015). 0 autor dis-

3 Tradução do autor: "No meio de Haight-Ashbury, nos anos '60, eu datilografava enquanto todos estavam tomando ácido ou fumando erva. Mas eu era conhecida por ter meu próprio espaço." 
cute como Rice desestabiliza noções de sexualidade, sobretudo no que concerne à validação da prática sexual e da violência, além de analisar a forma como a noção de poder está entremeada à da sexualidade.

É no aprofundamento de temas como a concepção e a validade de construções sociais que Rice dedicará grande atenção a temas como desejo, afeto, sinestesia e estética. Em The Witching Hour (1990) e The Vampire Lestat, a noção de família é posta em cheque, uma vez que a família Mayfair apresenta traços incestuosos; o mesmo acontece quando Lestat decide transformar sua mãe biológica em sua cria vampírica. O desejo homoerótico, latente em Interview with the Vampire, assume forma coerente em The Vampire Lestat, uma vez que Lestat transforma Nicolas, seu amante, mesmo tendo consciência de que, ao fazê-lo, estava-o destruindo. Por desejo, Lestat também transforma David Talbod, em The Tale of the Body Thief (1992),

"Let the flesh instruct the mind" numa relação que perpassa um reaprendizado dos sentidos, do desejo e do afeto entre criador e criatura. Nessa busca por sentido, frequentemente os personagens riceanos encontram algo significativo na estética e no corpo - o corpo, ora ou outra, aparece como vértice de experiências sensoriais redentoras. Em Memnoch The Devil (1995), Dora menciona seu intento de reformar a religião a partir de um "Evangelho da Carne".

A fim de melhor compreendermos como Anne Rice articula e entrecruza o tema da sinestesia às buscas espirituais/existenciais de seus heróis, analisaremos neste artigo o primeiro romance de Rice, Interview with the Vampire, romance que deu início às suas The Vampire Chronicles. Nosso objetivo aqui é discutir as representações corporais traçadas pela autora no drama de seus humanizados monstros. Como veremos, já em sua primeira obra - através da figuração de personagens como Louis, Lestat, Claudia e Armand - Rice propõe uma intensificação das percepções corpóreas e sensitivas, não apenas concernente à percepção da natureza e da arte, como também a do desejo, explicitando a energizada capacidade de seus heróis em apreender, vivenciar e recriar no corpo e através do corpo o entorno material.

\section{A redescoberta dos sentidos em Entrevista com o Vampiro}

Publicado em 1976, Entrevista com o Vampiro alcançou um grande reconhecimento tanto por parte do público como da maioria dos veículos jornalísticos pertinentes ao meio literário. A história começou a ser escrita em 1970, quando Rice cursava um mestrado em Escrita Criativa 
Andrio de

Jesus Rosa dos

Santos

Enéias Farias

Tavares na Universidade do Estado de São Francisco. Naquele ano, a perda de sua filha, Michelle, que veio a falecer aos quatro anos de idade em decorrência de um raro caso de leucemia, levou a aspirante à escritora a um momento sombrio, fazendo-a retornar à história de um vampiro amargurado e hiper-reflexivo.

Inicialmente um conto estendido, Entrevista foi crescendo em escopo e interesse, sendo também um canal usado por Rice para trabalhar seu luto. Críticos sem conta têm associado à criança vampiro Claudia a esse dado biográfico, dado ora negado ora confirmado por sua autora. Após participar de um encontro de autores e editores em 1974, Rice contratou Phyllis Seidel como sua agente. Seidel faria seu manuscrito chegar às mãos do editor Alfred Knopf, que comprou os direitos para publicação do livro. Foi dele o pedido para expandir o enredo, adicionando outro ponto de conflito à narrativa: o Teatro dos Vampiros. Apesar de suas primeiras críticas serem divididas, o livro vendeu mais de dez milhões de cópias desde seu lançamento, resultando em continuações que formariam as Crônicas Vampirescas da autora.

A trama do primeiro livro parte de uma entrevista realizada por um jovem jornalista na cidade de São Francisco com um misterioso homem que se apresenta como um vampiro. No decorrer da noite, o entrevistado, Louis de Pount du Lac, revela-se um verdadeiro imortal, contando ao seu interlocutor - e aos leitores - lembranças e reflexões que remontam ao final do século XVIII na cidade de Nova Orleans. Louis dá enfoque à sua relação algo conflituosa com seu criador, Lestat, assim como com a filha de ambos, a criança vampiro Claudia. Após Louis e Claudia fugirem de Lestat, o insuspeito casal parte à Europa, em busca de suas origens. A narrativa culmina em Paris, quando conhecem Armand, que vem, por obsessão a Louis, a tramar a morte de Claudia com outros imortais do Teatro dos Vampiros. Louis tem sua vingança exceto em relação a Armand - ao incendiar o Teatro, tornando-se uma alma errante e, aparentemente, um tanto desprovida de propósito. 0 romance finda com a derrota moral de Louis, uma vez que sua entrevista tinha o objetivo de alertar o entrevistador dos perigos e perversões da vida imortal. No entanto, o jovem interlocutor, ainda não nomeado, fascina-se com a história de Louis e pede a este que seja transformado em vampiro.

O romance insufla vigor nas narrativas vampíricas, uma vez que Rice desloca a ênfase da vítima para o monstro, dando voz ao imortal 
bebedor de sangue, concedendo nuances à narrativa de terror e horror, propiciando um estudo profundo sobre consciência, culpa, desejo e percepções estéticas e sensoriais. Além disso, Rice reinterpreta certos tropos da ficção gótica, como o final moralizante tão comum a esse tipo de ficção, algo não só relativo à derrota moral de Louis, mas também à tradição de literatura "vampírica". Carmilla (1872), de Le Fanu, e Dracula (1897), de Bram Stoker, apresentam monstros bebedores de sangue delineados a partir de personagens parcialmente criminalizadas, sobretudo no que diz respeito à sexualidade e ao gênero. Em Dracula, o vampiro se utiliza de uma mistura de terror e erotismo para seduzir suas vítimas, sendo destruído ao final do romance. Em Carmilla, Laura tem noção das intenções dúbias da vampira, o que por vezes sugere que ela irá tornar-se sua amante; no entanto, a voz de Laura de nada serve para seu pai, "Let the flesh instruct the mind" que orquestra a destruição de Carmilla. Ambos os casos servem como exemplo de como o mito do vampiro pode representar comportamentos sexuais não aceitos pelas convenções sociais vigentes.

Outra característica marcante de Entrevista está no estilo narrativo e textual de Rice. A autora trabalha com a linguagem de forma vívida, poética e absorvente, no intuito de evocar sensações mais do que descrevê-las. De fato, o emprego do estilo em prol da sinestesia é algo constante em sua obra. O que define o monstro riceano é justamente sua intensificada capacidade sentimental e discursiva, sendo sua maldição não apenas a imortalidade sob o custo de sangue humano, como também a desconexão de um mundo sempre mutável quando eles próprios são incapazes de mudar; e isso, obviamente, é extensível à relação que estabelecem com mortais, sendo suas vítimas ou não.

Dentre as questões destacadas acima, nos concentraremos no modo como a autora trabalha os sentidos e percepções corpóreas. Nosso objetivo é ler o romance de estreia de Rice a partir de sua postura ficcional que, além de contar uma história, parece explorar diferentes questões, sejam elas éticas ou estéticas. No caso da capacidade perceptiva, é como se a autora usasse a metáfora dos vampiros para aprofundar uma reflexão sobre os próprios limites dos sentidos corpóreos. Estes, ao serem intensificados pelo sangue sobrenatural de seus criadores, permitem novas sensações, experiências e apreensões de sua experiência existencial. Sobre essa característica da ficção de Rice, Katherine Ramsland afirma que Entrevista 
Andrio de

Jesus Rosa dos

Santos

Enéias Farias

Tavares

330 is full of highly charged sensuality. In a distinctive voice Anne Rice used voluptuous language and imagery to create subliminal tension and release that mimics sexual orgasm. The novel is erotic without explicit sex, creating a bridge between the impulse toward life deep within the psyche and the sensual excitement that could reach an audience. Tapping the physical agitation that accompanies fear, Anne provided a romantic adventure tinged with dark emotion and mystery. Her style was purposely ornamented with excessive language to create an atmosphere of sensory magnification. The story is told through passive, reflection, but it is full of restrained energy and movement (1992, p. 144).

O objetivo dessa linguagem densa, experimental e detalhada, segundo a pesquisadora e biógrafa, é "magnify human nature, not only in its capacity for sensory stimulation and eroticism, but also for loneliness, boredon, and vulnability" (1992, p. 171). Nesse aspecto, a dimensão sensorial da prosa de Anne Rice é um dos elementos mais destacados de sua ficção. Trata-se de uma ampliação da capacidade perceptiva e sinestésica de seus heróis malditos que, se por um lado os condena a uma existência monstruosa, por outro os torna criaturas para quem o desejo, os sentidos e a percepção tornam-se qualidades supremas. Esse "erotismo sem sexo", essa sensualidade "tingida de emoções sombrias e mistério" é um dos eixos centrais de seu romance de estreia. Na trama do romance, esse conjunto de percepções se expande em três objetivos específicos, que são a natureza, a cultura e a arte, eixos que o narrador Louis percorrerá gradualmente no decorrer da trama.

\section{Três paradigmas da percepção vampírica: entre a natureza, a cultura e a arte}

0 primeiro dos mencionados eixos ganha destaque em boa parte da narrativa, sobretudo por estar associado ao próprio narrador. Os outros dois - o da cultura e da estética - estão relacionados mais diretamente às presenças das personagens Lestat e Armand. No caso de Louis, essa especial observação da natureza precede sua transformação vampírica (RICE, 2009 [1976]). Neste caso, ainda em sua existência mortal, a percepção não vai além dos sentidos da visão e da audição, os elementos sinestésicos mais comuns à arte literária e não raro os mais exploradores 
por autores e narradores. A ênfase dada a esses dois sentidos no início da narrativa cria um ponto de contraste com o que ocorrerá posteriormente a Louis.

Após buscar a morte em tavernas e prostíbulos, devido à melancolia decorrente da morte de seu irmão, Louis é encontrado pelo vampiro Lestat, que vê nele a oportunidade de torná-lo um semelhante por aparentes interesses financeiros. Passada a sua transformação em vampiro, somos apresentados a uma sofisticada capacidade sensorial, diretamente atrelada à existência vampírica. Apesar das limitações textuais e narrativas para tal descrição - como o próprio narrador apresenta ao entrevistador ao afirmar "how pathetic is to describe these things which can't truly be described" (2009 [1976], p. 17) ${ }^{4}$ - Anne Rice não economiza detalhes à elaboração textual e narrativa da capacidade percep"Let the flesh instruct the mind" tiva de seus heróis vampiros. Neste quesito, o texto parece gradativamente revisitar cada um dos cinco sentidos corpóreos, numa renovada pedagogia dos sentidos que remonta aos decadentistas do século XIX. $O$ primeiro sentido detalhado por Louis é o da audição:

And then this next thing, this next thing was... sound. A dull roar at first and then a pounding like the pounding of a drum, growing louder and louder, as if some enormous creature were coming up on one slowly through a dark and alien forest, pounding as he came, a huge drum. And then there came the pounding of another drum, as if another giant were coming yards behind him, and each giant, intent on his own drum, gave no notice to the rhythm of the other. The sound grew louder and louder until it seemed to fill not just my hearing but all my senses, to be throbbing in my lips and fingers, in the flesh of my temples, in my veins (2009 [1976], p. 20) 5 .

4 "Quão patético é descrever essas coisas que não podem ser descritas". Nota dos Autores: Esta e demais traduções do romance pertencem à edição nacional da Editora Rocco, 1991.

5 E, em seguida, em seguida... um som. A princípio era um rugido rouco que depois se transformou num rufar, como o rufar de um tambor, cada vez mais alto, como se alguma imensa criatura estivesse saindo vagarosamente de uma floresta escura e estranha, rufando, enquanto andava, um enorme tambor. E, então, surgiu o rufar de outro tambor, como se outro gigante viesse atrás do primeiro e, cada gigante, preocupado com seu próprio tambor, não desse importância ao ritmo do outro. 0 som foi se - tornando cada vez mais forte até me dar a impressão de não estar apenas atingindo minha audição, mas todos os meus sentidos, de estar penetrando em meus lábios e em meus dedos, na carne de minhas têmporas, em minhas veias. 
$O$ destaque ao sentido do som opera em dupla via. Em primeira instância, como intensificação dos sentidos após a transformação vampírica. $\mathrm{O}$ que antes eram pequeninos sons ou mesmo sons imperceptíveis, como o bater de um coração, tornam-se agora um rufar de tambores, que Louis vai aprendendo a diferenciar. Além disso, a intensificação desse sentido,

Andrio de

Jesus Rosa dos

Santos

Enéias Farias

Tavares

332 em particular, resulta em intimidade entre o corpo do vampiro e do seu criador e, futuramente, entre aquele e suas vítimas. Na sequência desse primeiro sentido ampliado e intensificado, temos o sentido da visão:

"I saw as a vampire," said the vampire, his voice now slightly detached. It seemed almost distracted. Then he drew himself up. "Lestat was standing again at the foot of the stairs, and I saw him as I could not possibly have seen him before. He had seemed white to me before, starkly white, so that in the night he was almost luminous; and now I saw him filled with his own life and own blood: he was radiant, not luminous. And then I saw that not only Lestat had changed, but all things had changed. It was as if I had only just been able to see colors and shapes for the first time. I was so enthralled with the buttons on Lestat's black coat that I looked at nothing else for a long time" (2009 [1976], p. 21) .

A elaboração de formas e cores, figuras e elementos, similar ao som, também demora a ser diferenciada e compreendida. Trata-se do mesmo mundo, mas de um mundo agora alterado pelos "olhos vampíricos", fazendo de Louis um renovado infante encantado e absorvido não apenas por seu criador como também pelo mundo ao seu redor. $O$ "estar entretido com os botões do casaco" também pode aludir a outro sentido que parece aqui apenas sugerido, o do toque. Os vampiros de Anne Rice parecem eternamente imersos na capacidade de seus corpos imortais e poderosos servirem como receptáculo de sensações e impressões, impressão que marca cada página de suas narrativas.

6 - Vi como um vampiro vê - disse o vampiro, num tom ligeiramente mais lento. Parecia quase distraído. Então, voltou rapidamente a si. - Lestat estava novamente de pé na escada, e eu o vi como jamais poderia tê-lo visto antes. Antes, havia me parecido branco, inteiramente branco, tão intensamente branco que, à noite, me parecia quase luminoso. Agora eu o via com sua própria vida e seu próprio sangue: era radiante, não luminoso. E então percebi que não era apenas Lestat quem havia mudado, mas todo o resto também. - Era como se aquela fosse a primeira vez que percebia cores e formas. Fiquei tão entretido com os botões do casaco preto de Lestat que, durante algum tempo, não olhei para mais nada. 
Essas divisões entre ouvir e ver são fundidas numa sensibilidade híbrida, constituída a partir das mais variadas formas de sentir. Além da visão e da audição, outras alusões ao tato, olfato e paladar perpassam Entrevista, em muitos casos como se os corpos de seus personagens fossem compostos por tecidos sensoriais conectados a todos os elementos externos capazes de produzir sensações. Essa miscelânea de percepções sinestésicas - muitas vezes tratada como um "desnortear de sentidos" ("rapping of the senses", 2009 [1976], p. 30), para usarmos uma expressão da própria autora - culminará em passagens como a seguinte, na qual todas as percepções se misturam:

The old French city had been for the most part burned a long time ago, and the architecture of these days was as it is now, Spanish, which 118 meant that, as we walked slowly through the very narrow street "Let the flesh instruct the mind" where one cabriolet had to stop for another, we passed whitewashed walls and great courtyard gates that revealed distant lamplit courtyard paradises like our own, only each seemed to hold such promise, such sensual mystery. Great banana trees stroked the galleries of the inner courts, and masses of fern and flower crowded the mouth of the passage. Above, in the dark, figures sat on the balconies, their backs to the open doors, their hushed voices and the flapping of their fans barely audible above the soft river breeze; and over the walls grew wisteria and passiflora so thick that we could brush against it as we passed and stop occasionally at this place or that to pluck a luminescent rose or tendrils of honeysuckle. Through the high windows we saw again and again the play of candlelight on richly embossed plaster ceilings and often the bright iridescent wreath of a crystal chandelier. Occasionally a figure dressed for evening appeared at the railings, the glitter of jewels at her throat, her perfume adding a lush evanescent spice to the flowers in the air (2009 [1976], p. 151).?

7 Já fazia muito tempo que a velha cidade francesa tivera grande parte incendiada, e a arquitetura daquela época era como a de hoje, espanhola, o que significava que, ao andarmos lentamente pela ruela estreita onde um cabriolé tinha de parar para dar passagem a outro, passávamos por paredes caiadas e grandes portões que revelavam distantes pátios paradisíacos iluminados, iguais ao nosso, cada um deles parecendo conter uma promessa, um mistério sensual. Imensas, bananeiras tocavam os balcões internos, montes de samambaias e flores entupiam as entradas. Acima, no escuro, vultos sentavam-se aos balcões, com portas abertas às costas, suas vozes murmurantes e o rufar de seus leques quase inaudíveis sob a leve brisa do rio. E sobre os muros cresciam glicínias e trepadeiras tão exuberantes que esbarrávamos nelas ao passar, e às vezes parávamos para pegar uma rosa brilhante ou galhos de madressilva. Pelas altas janelas víamos várias vezes o jogo das luzes sobre tetos ricamente pintados e, frequentemente, a clara iridescência de um lustre de cristal. As vezes surgia na sacada um vulto vestido para a noite, o 137138 reluzir das joias ao pescoço, o perfume acrescentando um evanescente cheiro de luxúria às flores que recendiam no ar. 
Trata-se de uma fusão corpórea e alquímica, de um mergulho no mundo natural, absorvendo, no corpo e pelo corpo, todos os seus elementos constitutivos, todas as suas cores, formas, texturas, sons, perfumes e gostos. O narrador de Rice vive sempre embevecido por suas impressões sensoriais. Cada ambiente, pessoa ou elemento encontrado

Andrio de

Jesus Rosa dos

Santos

Enéias Farias

Tavares será um convite à interpretação sensorial. Antes de serem vampiros que bebem sangue, seus monstros são criaturas que se alimentam de percepções. Neste caso, essa percepção intensificada e atenta com frequência resulta em atmosferas altamente sensuais e eróticas.

Em contraste, a experiência mortal não passaria de um pálido reflexo, uma antecâmara sombria e defasada, para não dizermos desusada, em comparação às hiperbólicas capacidades sensoriais desses vampiros. Apesar de Louis os descrever como "intriguing soul clothed in rich, mysterious flesh" (2009 [1976], p. 64) ${ }^{8}$, frases como essa comunicam mais um fascínio em relação ao potencial sinestésico do corpo do que um interesse genuíno por seus possuidores, não raro tratados com irônica inferioridade. Os mortais que circundam essas criaturas de desejo e percepção são, por outro lado, aludidos como "groping, blind, preoccupied, and the brides and bridegrooms of death", em resumo, como um "wilderness of mortals surrounded us" (2009 [1976], p. 116) .

Louis, diferente dos mortais que encontra, está embevecido pela capacidade sensorial do corpo imortal. Como a próprio personagem afirma, ela está "rapt as I was with the world, fallen into the senses of the vampire, in love with color and shape and sound and singing and softness and infinite variation" (2009 [1976], p. 69) ${ }^{10}$. Essa versão intensificada, energizada ou vampirizada das percepções corpóreas domina todo o romance e, possivelmente, toda a obra de Rice, em especial suas Crônicas Vampirescas.

Em Entrevista, Rice também diferencia os alvos da fascinação perceptiva de seus dois protagonistas, um voltado para a natureza, como vimos, e outro para a cultura. Enquanto boa parte das observações sensoriais de Louis é direcionada ao mundo e aos seres humanos, ou ani-

\footnotetext{
8 Uma alma arrebatadora vestida por uma carne rica e misteriosa.

9 Uma quantidade fantástica de mortais nos cercava, tateando, cegos, preocupados e prometidos da noite.

10 Arrebatado como estava pelo mundo, sentindo como vampiro, apaixonando-me pela cor, forma, som, canto, maciez e infinitas variações.
} 
mais que o habitam, a percepção de Lestat parece se voltar para objetos domésticos e de vestuário. Vejamos como essa segunda dimensão aparece, inicialmente no modo como o próprio narrador Louis diferencia sua percepção da de seu criador:

And I tell you my frame of mind that night so you can know there are profound differences between vampires, and how I came to take a different approach from Lestat. You must understand I did not snub him because he did not appreciate his experience. I simply could not understand how such feelings could be wasted. But then Lestat did something which was to show me a way to go about my learning. He had more than a casual appreciation of the wealth at Pointe du Lac. He'd been

"Let the flesh instruct the mind"

O que define a natureza de Louis é a sua constante preocupação com questões filosóficas relativas ao mal, à vida e à morte. Por isso, o personagem encara o fascínio de seu criador por objetos manufaturados como possível evidência de sua artificialidade. Enquanto Louis parece dar à sua relação com Lestat tons comerciais e burgueses, Lestat - no futuro 0 Vampiro Lestat, romance em que o antagonista de Entrevista finalmente dá a sua versão da história - deixará claro que sua escolha por Louis se deu pela lembrança do seu amigo/amante, Nicolas, assim como pelas qualidades físicas do próprio Louis. Esse jogo de pontos de vista contrastantes será também uma qualidade de destaque da narrativa de Rice em suas Crônicas, muitas vezes ampliando narrativas e pontos de vistas anteriores.

11 E relato-lhe meu estado de espírito naquela noite para que possa entender que há profundas diferenças entre os vampiros, e como cheguei a ter uma impressão diferente de Lestat. Precisa compreender que não o critiquei por não valorizar sua própria experiência. Simplesmente não podia compreender como desperdiçava sentimentos como aqueles. Mas, então, Lestat fez algo que deveria me mostrar o caminho a seguir em minha aprendizagem. - Ele sentia mais que um mero apreço pela riqueza de Pointe du Lac. Tinha se extasiado com a beleza da porcelana servida a seu pai na ceia; gostava do toque das cortinas de veludo, e acompanhava os desenhos dos tapetes com a ponta do pé. E, naquele momento, pegou uma taça, em uma das cristaleiras, dizendo: - Sinto realmente falta das taças. 
Com a aparição de Claudia, o contraste entre as opostas percepções dos dois heróis permanece: Louis mais interessado em sua própria experiência e Lestat mais voltado para cores e texturas dos cortinados e outros utensílios que dão o tom da convivência dos três:

Andrio de

Jesus Rosa dos

Santos

Enéias Farias

Tavares

336

Lestat bought the very latest imports from France and Spain: crystal chandeliers and Oriental carpets, silk screens with aimed birds of paradise, canaries singing in great do domed, golden cages, and delicate marble Grecian gods and beautifully painted Chinese vases. I did not need the luxury anymore than I had needed it before, but I found myself enthralled with the new flood of art and craft and design, could stare at the intricate pattern of the carpets for hours, or watch the gleam of the lamplight change the somber colors of a Dutch painting (2009 [1976], p. 99) ${ }^{12}$.

Essa oposição entre as impressões advindas da natureza, de um lado, e da cultura, de outro - um tanto falsa e artificial, apesar de necessária para essa redescoberta dos sentidos realizada por Rice -, perderá peso no decorrer da trama, sobretudo depois da suposta morte de Lestat em Nova Orleans e da viagem de Louis e Claudia para a Europa. Mas antes de tratar dessa alteração de enredo e atmosfera, frisamos que o contraste entre Louis e Lestat é mais amplo e complexo do que o apresentado nessa primeira obra. $O$ que aqui parece artificialidade e insensibilidade por parte do vampiro criador, será revisitado e aprofundado em obras posteriores, revelando Lestat como o verdadeiro protagonista das Crônicas Vampirescas, um personagem através do qual Anne Rice poderá concretizar inteiramente seu projeto de exploração ficcional. Jennifer Smith coloca essa questão nos seguintes termos:

The progress of the Vampire Chronicles taken together reads as Rice's movement away from the guilt and passivity that Louis represents, through the passionate embrace of life and anarchy

12 Lestat tinha trazido para lá as últimas novidades importadas da França e da Espanha: candelabros de cristal e tapetes orientais, telas pintadas com pássaros do paraíso, canários cantando em grandes gaiolas douradas, um delicado deus grego em mármore e vasos chineses lindamente pintados. Eu não necessitava mais de luxo do que antes, mas me vi atraído pela nova invasão de arte, utensílios e formas, podendo fitar o intrincado desenho dos tapetes durante horas, ou ver o brilho de uma lâmpada modificar as cores sóbrias de uma pintura holandesa. 
that Lestat comes to represent in the later novels, and ends with the questions that Lestat is finally integrated enough to ask in the last novels (1996, p. 42).

Questões essas que, como os leitores de Rice sabem bem, continuam a aprofundar os temas da percepção corpórea e do desejo. Voltando a Louis, tal impressão contrastante de sua narrativa - entre as percepções de Lestat e suas próprias - será alterada quando encontrar Armand, personagem que encerra a capacidade de percepção estética máxima do romance, desviando o foco da natureza e da cultura para o da arte. É com ele, e na cidade de Paris, que Louis encontrará a quintessência dessa união, numa cidade que é igualmente bela e fascinante tanto por seus aspectos naturais quanto por seus monumentos humanos:

\author{
"Let the flesh \\ instruct the \\ mind"
}

\begin{abstract}
"But Paris, Paris was a universe whole and entire unto herself, hollowed and fashioned by history; so she seemed in this age of Napoleon III with her towering buildings, her massive cathedrals, her grand boulevards and ancient winding medieval streets-as vast and indestructible as nature itself. All was embraced by her, by her volatile and enchanted populace thronging the galleries, the theaters, the cafes, giving birth over and over to genius and sanctity, philosophy and war, frivolity and the finest art; so it seemed that if all the world outside her were to sink into darkness, what was fine, what was beautiful, what was essential might there still come to its finest flower. Even the majestic trees that graced and sheltered her streets were attuned to her -and the waters of the Seine, contained and beautiful as they wound through her heart; so that the earth on that spot, so shaped by blood and consciousness, had ceased to be the earth and had become Paris." We were alive again (2009 [1976], p. 204) ${ }^{13}$.
\end{abstract}

13 - Mas Paris, Paris era por si só um universo inteiro, cercada e modelada pela história. Era assim que parecia naqueles dias de Napoleão III, com seus prédios altos, suas catedrais maciças, seus imponentes bulevares e suas antigas e sinuosas ruas medievais - tão vasta e indestrutível quanto a própria natureza. Tudo era envolvido por ela, por seu povo volátil e cativante invadindo galerias, teatros e cafés, gerando, sem parar, gênio e santidade, filosofia e guerra, frivolidade e a mas pura arte; de modo que dava a impressão que todo o resto do mundo estava mergulhado em escuridão, o que era puro, belo ou essencial ainda devia ser procurado em seu seio. Até mesmo as majestosas árvores que enfeitavam e protegiam as ruas pareciam sintonizadas com ela - e as águas do Sena, calmas e belas ao recortarem seu coração; de modo que a terra naquele ponto, tão moldada por sangue e consciência, deixara de ser terra e se transformara em Paris. - Estávamos vivos de novo. 
Paris, nessa passagem, parece aglutinar as duas percepções anteriormente opostas: aquela da natureza, preconizada por Louis, em contraste com a da cultura, observada na fascinação de Lestat por utensílios domésticos e vestuários. Outro exemplo disso está na visita ao Teatro dos Vampiros, experiência que parece intoxicar ou desajustar

Andrio de

Jesus Rosa dos

Santos

Enéias Farias

Tavares os sentidos de Louis, fazendo com que todas as percepções possíveis se misturem num processo alquímico e vertiginoso no qual o ambiente inteiro, assim como suas criaturas, entorpece o narrador, culminando na descrição e efeito produzido por Armand (2009 [1976], p. 225).

Essa exuberância sensorial é então substituída pela percepção estética/artística, a terceira parte da tríade perceptiva trabalhada por Rice em seu romance. Essa instância é representada por Armand, até onde se sabe, o mais antigo dos vampiros naquela estranha, sórdida e fascinante comunidade. Como também será comum em outros livros de Rice - com especial ênfase a O Vampiro Armand e Sangue e Ouro, além de A História do Ladrão de Corpos - temos aqui a primeira descrição de obras de arte em sua narrativa. Neste caso, as pinturas assustadoras e de inconfundível tom sombrio que compõem o habitat dos atores vampiros:

I could see a world of frescoes and murals surrounded us, their colors deep and vibrant above the dancing flame, and gradually the theme and content beside us came clear. It was the terrible 'Triumph of Death' by Breughel, painted on such a massive scale that all the multitude of ghastly figures towered over us in the gloom, those ruthless skeletons ferrying the helpless dead in a fetid moat or pulling a cart of human skulls, beheading an outstretched corpse or hanging humans from the gallows. A bell tolled over the endless hell of scorched and smoking land, towards which great armies of men came with the hideous, mindless march of soldiers to a massacre. I turned away, but the auburn-haired one touched my hand and led me further along the wall to see 'The Fall of the Angels' slowly materializing with the damned being driven from the celestial heights into a lurid chaos of feasting monsters. So vivid, so perfect was it, I shuddered. (...) The candle rose. And horrors rose all around me: the dumbly passive and, degraded damned of Bosch, the bloated coned corpses of Traini, the monstrous horsemen of Durer, and blown out of all endurable scale a promenade of medieval woodcut, 
emblem, and engraving. The very ceiling writhed with skeletons and moldering dead, with demons and the instruments of pain, as if this were the cathedral of death itself (2009 [1976], pp. $227-228)^{14}$.

A representação do covil dos integrantes do Teatro dos Vampiros, sobretudo a dos cômodos de Armand, é constituída de referências a obras de arte, em sua maioria cenas de tom e autoria medieval. Também aqui vemos um tipo específico de comentário de arte que Rice também levaria para outros romances, numa espécie de "crítica estética" disfarçada de "trama ficcional". No que concerne aos sentidos, esse terceiro estágio do aprendizado sensorial de Louis - após passar por reflexões sobre a natureza e os utensílios humanos - agora encontra na arte um "Let the flesh instruct the mind" sentido último, relativo também a sua existência, sem dúvida um dos temas centrais do livro e também o fulcro de sua relação com a pequena vampira criança.

\section{A percepção vampírica de Claudia: "Let the Flesh Instruct the Mind"}

A prodigiosa criança vampiro tem um efeito estético sobre Louis, articulando, mesmo que indiretamente, os temas da percepção corpórea e do aprendizado moral do protagonista. Isso acontece a partir daquilo que Claudia chama de "vampire eyes", uma forma de "to see", de "drink the world", aparentemente ensinada a ela por Louis (2009 [1976], p. $113)^{15}$. O narrador sabe que o sentido que Claudia dá ao mundo e aos ou-

14 - Podia ver um mundo de afrescos e murais nos cercando, suas cores escuras e vibrantes sobre a chama trêmula, e aos poucos o tema e o conteúdo foram ficando claros. Era o terrível "Triunfo da Morte" de Brueghel, pintado numa escala colossal, onde a multidão de vultos espectrais flutuava sobre nós nas trevas, aqueles esqueletos miseráveis colocando a morte num fosso fétido ou puxando uma carroça de caveiras, decapitando um cadáver esticado ou pendurando humanos em forcas. Um sino repicava sobre o inferno interminável de terra ressequida e fumegante, para onde se dirigiam imensos exércitos de homens na marcha horrenda e desalmada dos soldados que vão para um massacre. Afastei-me, mas o ruivo tocou em minha mão e me fez seguir em frente, para ver "A Queda dos Anjos Rebeldes" se materializar lentamente, com os seres condenados sendo expulsos das alturas celestiais para um lúgubre caos de monstros que se banqueteavam. Era tão vívido, tão perfeito, que estremeci. (...) A vela se animou. E os horrores ressurgiram de todos os lados: os condenados taciturnos, passivos e degradados de Bosch, os cadáveres intumescidos em caixões, de Traini, os centauros monstruosos de Dürer e, se alastrando em escala insuportável numa série de entalhes, emblemas e gravuras medievais. Até o teto se contorcia em caveiras e cadáveres em decomposição, em demônios e instrumentos de torturas como se ali fosse a própria catedral da morte.

15 Mas você me ensinou a ver! - disse ela. - Você me ensinou as palavras "olhos de vampiro". Ensinou-me a sugar o mundo, a buscar mais do que... 
tros é diferente do seu, sendo mais voltado para uma percepção repleta de admiração e respeito pelo mundo e pela vida contida nele. Claudia, por outro lado, tem sua percepção voltada para uma "hunger for more", como se tudo relacionado aos sentidos, na percepção da criança vampiro, tivesse a ver com fome e desejo por posse e consumo - na acepção

Andrio de

Jesus Rosa dos

Santos

Enéias Farias

Tavares

mais básica e primitiva possível.

Em um momento fulcral do romance, quando a criança vampiro descobre sua origem - tendo sido vítima tanto de Louis quanto de Lestat -, ela afirma ao primeiro, enquanto projeta a vingança contra o segundo - seu "your vampire self more than you are", sua "need to drive the needle of the mind right to the heart of it all" (2009 [1976], p. 117) ${ }^{16}$. Se páginas antes Louis refere-se a Claudia como "my pupil, her long hours spent with me consuming faster and fasther the knowledge I gave her" (2009 [1976], p. 101), agora a situação inverte-se, uma vez que Claudia oferece a Louis - e Anne Rice a seus leitores - uma perspectiva emblemática sobre a forma de apreensão da experiência sinestésica:

“'You were right. He knows nothing. There is nothing he can tell us,' I said to her. “'Did you ever really that he did?' she asked me in the same small voice. 'We'll find others of our kind,' she said. 'We'll find them in central Europe. That is where they live in such numbers that the stories, both fiction and fact, fill volumes. I'm convinced it was from there that all vampires came, if they came from any place at all. We've tarried too long with him. Come out. Let the flesh instruct the mind'. I think I felt a tremor of delight when she said these words, Let the flesh instruct the mind. 'Put books aside and kill,' she was whispering to me (2009 [1976], p. 121, Grifo Nosso $)^{17}$.

16 Você precisa se aprofundar em tudo, como o bico do beija-flor que se agita com tanta pressa e força que os mortais chegam a pensar que não têm pés, não conseguiria parar, simplesmente indo de um lugar a outro, repetidamente, pelo prazer de fazê-lo. Eu represento seu ego de vampiro, mais do que você próprio.

17 - Você estava certa. Ele não sabe nada. Não há nada que possa nos dizer - eu falei. - Você realmente acreditava que pudesse? - ela perguntou com a mesma voz suave. - Acharemos outros de nossa espécie - disse. Iremos encontrá-los na Europa Central. É lá que existem em tal quantidade que as histórias, romanceadas ou verdadeiras, enchem volumes. Tenho certeza de que todos os vampiros vieram de lá, se é que vieram de algum lugar. Já hesitamos muito tempo com ele. Vamos. Deixemos a carne guiar a mente. - Acho que senti um arrepio de prazer quando ela disse tais palavras: Deixemos a carne guiar a mente. - Deixe os livros de lado e mate - murmurava para mim. 
Neste caso, o contraste entre Louis e Claudia se estabelece em nível moral e existencial, embora seja interessante notarmos como o narrador rapidamente equaciona esses eixos com eixos sensoriais e perceptivos. É como se a capacidade de sentir a realidade alterasse diretamente a profundidade moral e intelectiva desses personagens, como se ambas as esferas não estivessem separadas em suas consciências e percepções. Ao contrário, como se o corpo pudesse, através de seus sentidos, ensinar à mente a se posicionar moralmente diante da realidade. "Respeito" e "admiração sensorial" culminam, ao menos para Louis, em "respeito pela própria vida" e tal intersecção culminará na fórmula cunhada por Claudia, mas com sentido moral diametralmente oposto. A máxima de Claudia, "deixe a carne instruir a mente", refere-se ao imediatismo a partir do qual a vampira deseja agir, viver e amar; diferentemente de Louis, que se preocupa com códigos de conduta, morais ou religiosos. Sobre esse processo de autodesenvolvimento das personagens riceanos, Bette Roberts escreve:

\footnotetext{
In the postmodern world of Anne Rice, the Physically horrifying and the morally depraved Gothic villain-heroes are then transformed into sympathetic creatures who, like theirs human counterparts, must confront the existential realities of the late twentieth century. (...) Like their great Byronic ancestor they travel toward destruction, suffering, and renewal. The imprisonment from which they are delivered is not the stifling tyranny of men over women but that resulting from the Blakean mind-forged manacles, their own dependence on self-delusions concerning social institutions and religious myths (1996, p. 112).
}

Aqui, Roberts discute o tipo de caracterização que Rice apresenta em sua ficção, em contraste com a tradição gótica, à qual sua obra é frequentemente posta em paralelo. Porém, sua conclusão é contumaz ao aproximar Rice de um de seus mestres poéticos e espirituais, William Blake. Tanto a moralidade quanto as percepções sensoriais - essas costumeiramente associadas à culpa, pecado e queda - funcionam no Ocidente como "grilhões mentais", muitas delas "autoforjadas". Neste sentido, o arco dramático dos personagens de Rice se estabelece justamente como uma luta que objetiva destruir, em si mesmo, esses grilhões imaginários. 
A própria autora articula essa reflexão em outros momentos de sua produção e carreira. Em entrevista a Katherine Ramsland, por exemplo, ela afirma que o tema de A Rainha dos Condenados "is that the flesh teaches all wisdom and when we become too unanchored and get into abstract thinking that betrays compassion for the individual, that's

Andrio de

Jesus Rosa dos

Santos

Enéias Farias

Tavares
As Anne looks over her authorship, she notes that the novels draw together along similar themes. All of them are about the rich existence of people considered outsiders by normal social standards, and all emphasize the wisdom of experience over abstract ideas. "The books are always talking about truth being in the flesh," she explains. "They say that what the flesh desires is not necessarily bad, but requires exploration, attention" (1994, p. 33).

Como fica evidente, Rice está usando sua ficção para estudar os efeitos de uma questão bem mais complexa do que os comuns temas e situações do típico romance de terror poderiam sugerir. Através de seus vampiros - além de outros de seus monstros -, a romancista norte-americana parece estar tanto buscando uma compreensão da oposição corpo/mente ou corpo/espírito como também aprofundando os limites do debate no que tange ao papel da arte enquanto meio possível para a reflexão sobre o corpo e seus sentidos. Neste caso, uma pesquisa que teria início em seu primeiro livro e que retornaria em outras obras.

No desenlace de Entrevista com o Vampiro, Louis vinga-se dos vampiros do Teatro por terem assassinado Claudia. Com isso, o narrador tenta substituir sua passividade por um maior poder de ação, a fim de levar a termo sua vingança. Sua conclusão é a seguinte:

I never changed after that. I sought for nothing in the one great source of change which is humanity. And even in my love and absorption with the beauty of the world, I sought to learn nothing that could be given back to humanity. I drank of the beau- 
ty of the world as a vampire drinks. I was satisfied. I was filled to the brim. But I was dead. And I was changeless. The story ended in Paris, as I've said (2009 [1976], p. 321) ${ }^{18}$.

Aqui, o paradoxo é gritante. Há, nas mais de trezentas páginas do romance, um estudo por parte do narrador de tudo aquilo que ele teria aprendido em sua existência vampírica e, como visto, boa parte desse aprendizado envolve a capacidade perceptiva do corpo. Todavia, após o encontro com Armand e sua vingança, Louis insiste que não mais alterou sua percepção e continuou, a despeito de seu "amor e enlevo pela beleza do mundo", inalterado ou imutável.

Na verdade, acreditamos que Anne Rice, na sua necessidade de não apenas findar o enredo de seu romance como também de dar uma

"Let the flesh instruct the mind" conclusão coerente ao seu sensível protagonista, tenha chegado ao limite do que poderia aprofundar ou problematizar em uma personagem como Louis. Natureza, cultura e arte são as estações da paixão desse protagonista, um herói melancólico e um tanto passivo diante das violentas sensações do mundo. Como resultado, temos um enfastiado niilismo, algo tão pouco em concordância com as vivências e ocorrências de todo o romance, um texto cuja bússola principal é justamente a busca incessante por um sentido existencial através dos sentidos corpóreos.

Assim, objetivando seguir em sua reflexão sobre as capacidades sensoriais e os sentidos criados a partir delas, a autora se volta para outra de suas personagens, um herói para quem a capacidade de agir é condição primal e que, talvez por isso, acabou se tornando o verdadeiro herói de suas Crônicas. Se em Entrevista ele foi visto e tratado como um vilão trágico, em romances futuros, Lestat dará voz às suas memórias e - também - ao seu aprendizado sinestésico, encontrando na expressão “Jardim Selvagem” seu perfeito ideário.

\section{Conclusão}

Em Entrevista com o Vampiro, há um movimento tríplice no que concerne à problemática sensorial, a saber: percepções da natureza, percepções de utensílios domésticos e vestuários e percepções de arte. A primeira

18 - Depois disso nunca mais mudei. Não busquei nada na imensa fonte de transformações que é a humanidade. E mesmo em meu amor e enlevo com a beleza do mundo, não procurei aprender nada que pudesse reverter para a humanidade. Suguei a beleza do mundo como um vampiro. Ficava satisfeito. Enchia-me até a borda. Mas estava morto. E era imutável. A história terminou em Paris, como já disse. 
Andrio de

Jesus Rosa dos

Santos

Enéias Farias

Tavares

344 delas é o que identifica Louis, a segunda, Lestat e a terceira, Armand, estando essas três instâncias interconectadas no discurso do primeiro, o narrador do romance. Além disso, Louis parece, no decorrer de seu desenvolvimento, experimentar cada uma dessas instâncias a partir daquilo que compreendemos como um reaprendizado da capacidade sensorial ou da percepção sinestésica.

Apesar de Anne Rice evitar pedagogismos simplórios, sua ficção apresenta uma forma de reeducação perceptiva, usando a arte e seus heróis amaldiçoados para reconstituir em seus leitores uma intensificada capacidade de ver, ouvir, tocar e sentir. Nesse aspecto, ela não estaria longe de William Blake e sua expansão das Portas da Percepção nem de Oscar Wilde e de outros dândis finisseculares, para quem a percepção estética era também uma via para uma percepção existencial expandida e intensificada.

Esses dois nomes são onipresentes na ficção de Rice, estando os três em acordo de que o dualismo corpo/mente não passaria de uma trágica e prejudicial aporia, um paradoxo ou impossibilidade em essência. Uma vez que as vias de acesso, formação e percepção da mente não existem dissociadas do corpo e de seus canais perceptivos, como separar uma coisa da outra? Ainda mais, como compreendê-las e intensificá-las? Numa fria noite de 1976 em um quarto pouco iluminado na cidade de São Francisco, uma inusitada conversa parece ter sugerido se não uma resposta, o princípio de uma convidativa pergunta. Pergunta que Anne Rice trabalharia para responder nas décadas seguintes em suas Crônicas Vampirescas.

\section{REFERÊNCIAS}

DOANE, Janice; HODGES, Devon. Undoing Feminism: From the Preoedipal to Postfeminism in Anne Rice's Vampire Chronicles. In: American Literary History, Vol. 2, No. 3, 1990, p. 422-442, Oxford University Press. Disponível em: <www.jstor.org/stable/489948>. Acesso em: 05/03/2019.

HOPPENSTAND, Gary. BROWNE, Ray B. (Ed.) The Gothic World of Anne Rice. Bowling Green: Bowling Green State University Popular Press, 1994. 
LE FANU, Sheridan. Carmilla (1872). Disponível em: <http://www. gutenberg.org/files/10007/10007-h/10007-h.htm>. Acesso em:13/03/2017.

PAOLUCCI, Peter Leonard. Re-Reading the Vampire from John Polidori to Anne Rice: Structures of impossibility among three narrative variations in the vampinc tradition. Toronto: York University, 2010.

RAMSLAND, Katherine. Prism of the Night - A Biography of Anne Rice. New York: Plume, 1992.

Let the flesh instruct the mind"

RAMSLAND, Katherine. The Lived World of Anne Rice's Novels. In: HOPPENSTAND, Gary. BROWNE, Ray B. (Ed.) The Gothic World of Anne Rice. Bowling Green: Bowling Green State University Popular Press, 1994, p. 13-34.

RICE, Anne. A História do Ladrão de Corpos. Trad. Aulyde Soares Rodrigues. Rio de Janeiro: Rocco, 2009.

RICE, Anne. Entrevista com o Vampiro. Trad. Clarice Lispector. Rio de Janeiro: Rocco, 2009.

RICE, Anne. Essay On Earlier Works, 15 Ago. 2007. Disponível em: <http://www.annerice.com/Bookshelf-EarlierWorks.html>. Acesso: 04/01/2017.

RICE, Anne. Memnoch, the Devil. New York: Ballantine Books, 1997.

RICE, Anne. O Vampiro Lestat. Trad. Reinaldo Guarany. Rio de Janeiro: Rocco, 1999.

RICE, Anne. o Vampito Armand. Trad. Adalgisa Campos da Silva. Rio de Janeiro: Rocco, 2000.

RICE, Anne. The Queen of the Damned. Ballantine Books, 1997.

RICE, Anne. The Tale of the Body Thief. New York: Ballantine Books, 1993. 
RICE, Anne. The vampire Armand. New York: Ballantine Books, 1998.

RICE, Anne. The vampire Lestat. New York: Ballantine Books, 1985.

RICE, Anne. The Witching Hour. New York: Ballantine Books, 1990.

Andrio de

Jesus Rosa dos

ROBERTS, Bette B. Rice and the Gothic Tradicion. In: BEAHM, George.

Santos (Ed.) The Unaughorized Anne Rice Companion. Kansas: Andrews and McMeel Books, 1996, pp. 107-119.

Enéias Farias

Tavares STOKER, Bram. Dracula. New York: Signet, 1965.

346 SMITH, Jennifer. Anne Rice: A Critical Companion. Westport: Greenwood, 1996. 